\title{
Ciencia política en Chile: UN ESPEJO INTELECTUAL
}

\author{
María de los Ángeles Fernández* \\ Escuela de Ciencia Politica, Universidad Diego Portales, Chile
}

\begin{abstract}
Resumen
Al igual que el resto de las ciencias sociales, la ciencia política chilena está en deuda con su historia. Si bien existen reflexiones puntuales, más bien descriptivas, sobre la disciplina, no se ha desarrollado un análisis auto-reflexivo sobre su devenir como disciplina y profesión. A pesar de su relativa juventud, es ésta una tarea pendiente que, de enfrentarse, puede contribuir a hacer sentido acerca de su rol y naturaleza. A partir de la utilización del enfoque internalista, se recurre a la aplicación de entrevistas a cientistas políticos a fin de auscultar la percepción y las imágenes que los propios cultores tienen de temas relacionados con la vocación, la concepción de lo político y los ideales explicativos de la disciplina, los referentes disciplinarios, su función y relevancia social, sus fortalezas y posibilidades. Se propone, entonces, un primer relato que contribuya a una mayor sensibilización acerca del pasado y del futuro de la disciplina.
\end{abstract}

Abstract

Political science, like the other social sciences in Chile, is in debt with its history. While there have been some specific and descriptive reflections, an analytical reflection about its development as a discipline and profession is necessary. Despite the relative youth of political science in Chile, such a task can help us make sense its role and nature. Using an internalist approach and interviews with Chilean political scientists, the article examines perceptions and images about issues related to political science as a vocation, how the study of politics has been conceptualized historically, its references, its function and social relevance, its strengths and possibilities. The result is an account which may serve as a first step towards the creation of an increased sensibility for the past and the future of the discipline in Chile.

PALABRAS CLAVE • Ciencia Política • Historia • Chile • Disciplina

\section{INTRODUCCIÓN}

En América Latina, carecemos de registros de nuestra memoria intelectual. Así lo advierte Lechner (1997:33) cuando afirma que tenemos poca tradición en dar cuenta de nuestro quehacer, pasando de tema en tema, de coyuntura en coyuntura, sin hacer memoria.

A pesar de ello, para el caso de Chile es posible rastrear algunas reflexiones sistemáticas sobre las Ciencias Sociales (Fuenzalida, 1983; Brunner, 1985, 1988, 1989; Brunner y Barrios, 1987; Courard y Frohmann, 1999; Garretón, 1981, 1989; Lechner, 1988; Lechner et al., 1991; Fuenzalida, 2001). Es importante reseñar las reflexiones realizadas para el caso específico de la Sociología (Barrios y Brunner, 1988; Brunner, 1988).

Sin embargo, ¿a qué podemos recurrir, con relación a la ciencia política? En verdad, nada mucho más allá que el intento de análisis de individuos aislados, citando a Rose (1990: 581). Cualquiera

* Mucho agradezco los comentarios de David Altman y de Patricio Navia a una versión preliminar del presente artículo. 
que quisiera seguir el rastro de la evolución y desarrollo de la ciencia política en el Chile contemporáneo, tendría que recurrir a los análisis que se centran en aspectos específicos de su desarrollo como disciplina y que denotan cierto descriptivismo cuando no la carencia de marcos de análisis más generales y genéticos. En este contexto, las relaciones internacionales también han merecido una reflexión especial, como área especializada al interior de la ciencia política (Sepúlveda, 1976; Wilhelmy, 1978; Huneeus, 1988; Godoy y Vial, 1989; Lechner, 1990; Sepúlveda, 1996; Tomassini y Ortiz, 1999; Ortiz, 1999; Fernández, 2003a, 2003b).

Hoy día, estamos mejor premunidos para enfrentar estos esfuerzos, dado que la ciencia política ha llegado a disponer de recursos, tanto teóricos como epistemológicos, para enfrentar su autoanálisis e introspección. Nos referimos a un cuerpo de instrumentos analíticos y conceptuales especializados en la historia de la Ciencia Política, surgido al alero del clima post-positivista. Si bien se encuentra todavía en estado de take off o embrionario, ya a fines de los años ochenta no era una exageración sugerir que caminaba a convertirse en un campo distintivo de investigación (Gunnell, 1991: 16; Berndtson, 1991: 38; Almond, 2001:126). Esta empresa intelectual parte del supuesto de que habría una lógica interna a la disciplina que puede explicar, en parte, la forma en que se ha desarrollado a lo largo del tiempo. En coherencia con ello, cada cuerpo de conocimiento tiende hacia una relativa autonomía desde su ambiente intelectual y social y, para comprenderlo, se necesita auscultar la forma en que un tipo de discurso tiene sus propias asunciones, lenguaje y lógica, así como su propio criterio para determinar lo que será aceptado como evidencia. De acuerdo a esto, la disciplina en sí misma, así como su ubicación universitaria, sería el contexto más relevante (Easton et al., 1995:2; Gunnell, 2004: 9).

En el presente artículo presentamos un primer boceto intelectual del desarrollo de la Ciencia Política en Chile, a partir de la mirada de sus propios cultores. Mediante la aplicación del enfoque internalista, que enfatiza las dinámicas del cambio conceptual al interior del discurso de la ciencia política, se muestra, por una parte, una primera revisión historiográfica, la que contribuye al desarrollo de la identidad de la disciplina y a pesquisar la utilidad de dicho enfoque, para el caso chileno. A través del recurso de la entrevista ${ }^{1}$, se aplicó dicha técnica a veinticinco cientistas políticos, de distintas edades y sub-áreas de especialización, todos hombres a excepción de dos mujeres. La selección de personas a entrevistar no se realizó a partir de criterios rígidos y rigurosos de muestra o representatividad, aunque se logró el equilibrio por edades e influencias formativas distintas. El método escogido resulta idóneo porque, siguiendo a Gunnell (2004), se apoya en una opción epistemológica que permite enfatizar y resaltar las dinámicas del cambio conceptual dentro del discurso de la ciencia política, asumiendo que las percepciones de los politólogos sobre el lugar político en el que se encuentran y las relaciones de la disciplina con él son cruciales $y$, en segundo lugar, porque pareciera pertinente analizar la ciencia política en cada país de acuerdo a su propio contexto y usando métodos de los estudios culturales e históricos, recurriendo en ciertos casos a la indagación del rol que académicos individuales han desarrollado en la historia de la ciencia. En este ámbito específico, se trata de visualizar a los actores como sujetos históricos y como objetos de eventos, instituciones, funciones y estructuras (Berndtson, 1991: 45).

Los cientistas políticos, entrevistados entre agosto del 2002 y octubre del 2004, fueron los siguientes: Alfredo J oignant, Alicia Frohmann, Angel Flisfish, Arturo Valenzuela, Augusto Varas, Carlos Fortín, Carlos Huneeus, Carlos Miranda, Claudio Fuentes, Eduardo Ortiz, Fernando Molina, Fernando Moreno, Gabriel Gaspar, Gustavo Martínez, Ignacio Walker, Jorge Heine, Jorge Nef, Luciano Tomassini, Mercedes Aubá, Norbert Lechner, Oscar Godoy, Patricio Navia, Ricardo Israel, Roberto Durán y Tomás Chuaqui. 
De acuerdo a estos planteamientos, pareciera de interés develar los argumentos tal como ellos emergen en las entrevistas, más que racionalizarlos en términos de alguna estructura conceptual. Nos interesa captar las representaciones que sus cultores se hacen de la ciencia política en términos de imágenes de sus discursos y prácticas.

Para ello, nuestra hoja de ruta enfatiza la ubicación de esta empresa en el marco más amplio de intentos visibles que se han realizado para comprender la historia intelectual de la ciencia política, las razones de su evidente retraso frente a las trayectorias realizadas en otras disciplinas y su utilidad y pertinencia. En segundo lugar, en base a un conjunto de lineamientos de indagación histórica que el estudio del desarrollo de la ciencia política comparada ha identificado hasta el momento, pesquisaremos las visiones existentes en los cientistas políticos chilenos en torno a cómo se llega al interés por la política y por el estudio de la política (la vocación), la influencia del contexto y las posibilidades de autonomía de la ciencia política en Chile, la influencia del régimen político en su desarrollo y cómo se visualiza el impacto de la hegemonía disciplinaria americana, sus percepciones acerca de la relación estudiante-profesor, la función social que tiene o potencialmente podría cumplir la disciplina y la identificación de los referentes individuales disciplinarios, en el contexto más amplio de cauces generacionales. Como conclusión, junto con mostrar ciertas configuraciones de discurso, obtendremos un boceto de las visiones de los politólogos chilenos con relación a su propia práctica disciplinaria.

\section{ENTRE HISTORIAS, PERFILES Y AUTORRETRATOS}

A partir de la década de los 80 se han realizado esfuerzos de introspección disciplinaria, tanto en la línea de generar un cuerpo de conocimiento de utilidad para el análisis comparado como para el estudio específico de casos por países. Hasta ese momento, sólo en Estados Unidos se había desarrollado un esfuerzo historiográfico consistente, además del conocido balance publicado por la UNESCO sobre la ciencia política contemporánea en la década de los años 50, así como referencias someras en diccionarios o enciclopedias especializadas (J erez Mir, 1999:40).

Para los impulsores de esta área nueva de estudio, denominada "Historia de la Ciencia Política", la relevancia de este campo radica en el deseo de comprender los factores, tanto internos como externos a la ciencia política, que han sido compartidos en el pasado, lo que permitirá una mejor anticipación y guía para su desarrollo futuro. La historia aparece como una importante fuente de auto-identificación, que puede servir al progreso teórico y metodológico de la ciencia política, y sus lecciones van más allá del mero conocimientos de ciertos mecanismos evolutivos (Anckar y Berndtson, 1987: 6; Dryzek y Leonard, 1995: 27, 43, 44). Para autores como Kenny (2004: 565) y como Adcock y Bevir (2005:1) es importante el sentido que se posea de la historia disciplinaria, puesto que este sería un importante aspecto de la identidad de una disciplina académica, independientemente de lo diversa que ella sea en términos de sus objetos de estudio, métodos de indagación y tradiciones teóricas. La historia de la ciencia política es una fuente de identidad disciplinaria.

Llegar a este estado de cosas no ha sido ni fácil ni rápido: a decir de Gunnell (1991: 14; 2002: 353), la ciencia política le prestó menos atención sistemática a la investigación de su pasado (en relación, por ejemplo, a la psicología o a las ciencias duras), adjudicando la responsabilidad de ello a las características estructurales del campo (particularmente, al efecto inhibitorio de la autorreflexión 
que produciría el estudio de la historia de la teoría política), así como a la influencia a-histórica del positivismo y al carácter aburrido y escasamente romántico de mucho del material de estudio de la disciplina. Sin embargo, esta situación parece haberse revertido, favorecida por las nuevas tendencias en la historia de las ciencias, tanto naturales como sociales, que han avanzado en una transformación sustancial de su auto-imagen, en el marco más amplio de la atmósfera reflexiva que se genera en el actual contexto post positivista y por el impacto específico de ciertos desarrollos realizados en el estudio de la historia intelectual (Graham et al., 1983: 22; Gunnell, 1991: 21).

Una sugestiva variante de la historia de la disciplina es aquella que se centra en la historia de la profesión (J erez Mir, 1999: 47). En este contexto, nadie duda que los cientistas políticos norteamericanos son los que más se han autoanalizado, realizándose sistemáticos perfiles de quiénes componen la profesión, rankings de prestigio y sus visiones de mundo, especialmente bajo los impulsos de la American Political Science Association (Lynn, 1983: 95). Asimismo, en este mismo país destacan proyectos de orden más cualitativo como Political Science in America: oral histories of a discipline, de Baer et al., publicado en 1991, que supone un esfuerzo por encontrar las raíces intelectuales de la ciencia política a través del estudio de entrevistas con prominentes cultores de la misma, a partir de la constatación de una relativa inconciencia de los politólogos acerca de su pasado disciplinario.

Por su parte, en Comparative European Politics: the story of a profession (1997), Hans Daalder provee las biografías intelectuales de 33 académicos que han contribuido al desarrollo del estudio de la política comparada europea desde la Segunda Guerra Mundial. Con el objetivo de tomar en cuenta diferentes enfoques y paradigmas, cada académico fue invitado a analizar su propio trabajo, desde las experiencias políticas de sus años formativos como mediante la indicación de los libros y académicos que tuvieron influencia en su desarrollo intelectual.

De alcances más modestos La Ciencia Política de fin de siglo, de César Cansino (1999), reúne la reflexión de los principales representantes de la ciencia política contemporánea sobre el presente y el futuro de la disciplina.

A renglón seguido, y siguiendo el espíritu de los ejercicios de autorreflexión anteriormente indicados, intentaremos identificar, describir y analizar cierto tipo de problemas para comprender la evolución de la ciencia política en Chile, a partir del material que nos suministran las entrevistas realizadas a cientistas políticos chilenos. Los temas seleccionados se inspiran en el conjunto de aspectos y factores significativos a tomar en cuenta cuando enfrentamos el estudio auto-consciente de la disciplina, reconociendo que es un listado efectuado con un sentido preliminar y tentativo dado que, en ciencia política, no existe todavía un consenso acerca de la naturaleza de su coherencia teórica. Frente a la carencia de una integración teórica aceptable de la disciplina, sólo sería posible delinear un conjunto de lineamientos de indagación histórica que se sospecha como los más adecuados para describir y descubrir cómo la disciplina ha llegado a ser lo que hoy es (Easton et al., 1995: 4).

\section{III. ¿CÓMO LLEGAMOS A SER LO QUE ESTUDIAMOS?}

Berndtson (1991) ha señalado que una historia disciplinaria debería clarificarse desde los diferentes sesgos que emergen del proceso de socialización de los politólogos. Al parecer, pocos politólogos están dispuestos a estudiar su propio comportamiento racional y no suelen aplicarse 
los métodos que usan para otras investigaciones. Se refiere a temas tales como el aprendizaje de las reglas para ser un buen cientista politico, conocer el tipo de personalidades que ellos poseen y el problema del reclutamiento, dirigido a responder la pregunta de qué tipo de personas estudian ciencia política y quiénes son reclutados dentro de la profesión. Resulta difícil señalar un motivo general (salvo cuando se realizan estudios de cortes generacionales), pero lo que parece estar claro es que ni el dinero ni la fama son los principales incentivos. En lugar de ello, una cierta fascinación con el poder o una motivación fuerte para reformar el sistema parecieran ser los principales motores que llevan al estudio de la ciencia política.

En este contexto, de acuerdo a las entrevistas realizadas, los ámbitos de socialización política más notorios son la familia, particularmente cuando existe una tradición de servicio público e impera un ámbito cultural estimulante, así como el colegio. Inclusive, a pesar que los medios de comunicación no ejercían en esos años la influencia que vemos en la actualidad, parecen inclinar la balanza en algunos casos:

Creo que yo fui una mutante. En mi familia de origen, a nadie le interesaba nada la política. Pero, por alguna razón, desde chica escuchaba en la radio a Hernández Parker y a Lenka Franulic. Me recuerdo escuchándola cuando yo tenía como cinco o seis años. En mi familia, me miran como bicho raro.

Lo que se denomina una "socialización de viajes" parece haber jugado un rol relevante, a juzgar por los testimonios:

Tengo una socialización de viajes y también pesa la noción del orden, vinculada a la Segunda Guerra Mundial y sus efectos, así como el tema de la identidad, vinculada a los mismos viajes, porque siempre tengo que definirme quién soy.

Mi padre sentía fascinación por la historia de Europa. Cuando yo tenía once años, mis padres me llevaron a Europa y, dado que habíamos estudiando en la Alianza Francesa, en Concepción, sabíamos mucho de historia de Francia. Fue un privilegio y una cosa muy excitante.

Pero, sin lugar a dudas, el hito fundamental para los cientistas políticos chilenos pareciera ser el quiebre de la vida democrática acaecido el 11 de septiembre de 1973. A partir de ahí, nada parece haber sido igual en sus vidas. El impacto de este suceso político ha surtido, bien efectos directos, bien por derivación, como es el caso de politólogos que vivieron la experiencia del exilio, como consecuencia del compromiso político de sus padres. Es conveniente indicar cómo, en algunos casos, los acontecimientos previos a esa fecha, tales como la Reforma Universitaria, calaron hondo en la decisión de buscar herramientas teóricas para comprender la realidad de ese momento. Igualmente, la mayoría de los entrevistados habían estudiado Derecho con anterioridad, lo que les había dejado una insatisfacción profunda por su incapacidad para otorgarles claves de comprensión para lo que estaba aconteciendo. Se llega al estudio de la política, en algunos casos, por un afán de rigor científico:

Mi interés por la política viene a despertarse recién al ingresar a la Escuela de Derecho de la Universidad de Chile, en 1966. 'La Escuela', como es conocida, ha sido tradicionalmente el semillero de la dirigencia política en Chile. En esos años se produjo la reforma de los estudios de derecho, cambiando también la metodología de enseñanza mediante la introducción de seminarios y talleres que potenciaban la discusión y que eran dictados por personas como 
J orge Arrate, Juan Bustos, Daniel Moore, Elio de la Vega, Cecilia Medina, Waldo Fortín, Hernan Fischmann y Myriam Waiser, entre otros. Por otra parte, se estaban iniciando fuertes procesos de Reforma Universitaria en las Universidades de Chile y la Católica.

La política tenía una fuerte presencia en mi vida, esencialmente, por la lógica de las responsabilidades de mi padre, que había asumido funciones en el gobierno de Salvador Allende... Pero, después del golpe, la política adquiere otro rostro, más doloroso, producto de la prisión de mi papá durante tres años y el exilio, posterior a la cárcel. Mi padre se aleja de la controversia interna del Partido Socialista y eso llega a mí, cuando vivimos en Francia, con la llegada de Miterrand al poder, que es un momento muy importante para todos nosotros ya que, en sus inicios, fue muy épico.

Mi interés por la política está anclado en la experiencia de la dictadura. Mi familia es de clase media, profesores y, cuando yo era joven, mis hermanos mayores ya estaban en la Universidad y se habían involucrado en política. De ahí viene mi participación en las protestas (...)

No tenía la menor idea respecto de qué podía ser la ciencia política, pero la explicación de Carlos (Fortín) sobre el anhelo de rigor científico, particularmente en términos de una aproximación empírica al objeto de investigación, en el estudio de los fenómenos políticos, me sedujo bastante. Parecía ser lo contrario de las disciplinas jurídicas tal como se practicaban en Chile: formalismo, escolasticismo, lógica deductiva ramplona. Ello fue lo que me motivó, y no tanto que se tratan de estudiar 'la política'.

Relacionado con lo anterior, y dado que el ejercicio de la actividad política se convierte en algo prohibido, ejerce niveles de atracción que lleva a la fascinación por conocer más sobre aquello de lo que se habla sólo a escondidas:

En realidad, y por la actividad académica de mi padre, mi interés original por la política surge porque era algo relativamente prohibido, se hacía en secreto, se hacía en la casa (... )

Fuimos a Argentina, después de la guerra de las Malvinas, y empezaba a aparecer información en los diarios sobre los derechos humanos, el juicio a los militares y la justicia investigando cosas. Eran cosas que en Chile no se leían a pesar de que se decía que había pasado algo similar. Le pregunté a mi papá, quien me dijo que un tío mío había estado en el Estadio Nacional para 1973. Eran temas prohibidos, de los que se no se hablaba, y me pareció fascinante saber por qué (...).

En algunos casos, los momentos de agitación política previos al 11 de septiembre de 1973, y la opción que la Iglesia Católica tomó por los desposeídos primero, y los perseguidos después, inclinó la balanza por el estudio de los fenómenos políticos:

Soy parte de una generación que venía de un origen conservador y que asume una visión de la Iglesia Católica en términos de renovarla. Pequeños grupos de elite en los colegios, las universidades, las profesiones, empiezan a preocuparse por la renovación del cristianismo.

Además de la tradición familiar y de la vocación pública, fuertemente arraigada en mi familia, también influyó la Iglesia, particularmente en los años 70 y 80 . Soy un cristiano en política. 
Sin embargo, también existen casos excepcionales de derivación hacia el estudio de la política sin la existencia de factores condicionantes previos, y en los que primó más un interés intelectual genérico:

En mis tiempos de estudiante, nunca tuve una particular afección a lo que podíamos llamar política. Participaba disciplinadamente de las reuniones de grupo, me encargaba del diario mural, pero mi interés era más intelectual. Yo venía con un grupo de compañeros, todos los sábados, a una editorial que tenía el partido democratacristiano en la calle Ahumada, donde estaba Jaime Castillo.

En casos muy puntuales, la llegada a la ciencia política es un producto de la exigencia laboral:

Te diría que, en realidad, me fui deslizando hacia la ciencia política a través de la práctica laboral, de la participación en seminarios, conferencias, investigaciones y lecturas. Se produjo por mi llegada a FLACSO, y coincide con mi alejamiento al tipo de trabajo historiográfico en sí mismo.

El impacto definitivo de ciertos eventos a la hora de abrazar el estudio de la disciplina, para el caso de los cientistas politicos chilenos, abre interrogantes a la hora de entender los factores que llevan a las nuevas generaciones, en un contexto de normalidad democrática, a estudiar ciencia política. Pero éste es un tema que escapa a los objetivos del presente trabajo.

\section{AUTONOMÍA Y CONTEXTO DISCIPLINARIO: SU RELACIÓN CON EL RÉGIMEN POLÍTICO}

Concordar puntos de vista comunes sobre lo que se entiende por autonomía y contexto levanta las mayores controversias entre los estudiosos de la historia disciplinaria. En el primer caso, pudiera referirse no sólo con relación a otros campos (o la ecología académica, que en Chile aparece como una variable importante), sino también a su vinculación con la empresa científico-social como un todo y con prácticas políticas, en general, así como con cuestiones metodológicas, relativas a la comprensión de la historia del campo. Pudiera asumirse que la ciencia política, en gran medida, toma forma y se autodefine en respuesta a la configuración de la política que emana de una sociedad dada. Pero también surgen preguntas acerca de si es posible concebir un cuerpo universal de conocimiento con posibilidad de trascender las tradiciones locales y la cultura en la que está inserta. En el segundo caso, resulta dificultoso encontrar una definición unívoca, ya que puede entenderse como influencia, impacto, contribución, causa, interacción, etc. Una visión restringida nos remitiría a la naturaleza de las instituciones académicas y a la universidad, o bien a un conjunto de eventos sociales y políticos particulares. Una visión más amplia incluiría a la sociedad completa, su estructura social y el modo de producción. Mención aparte merece el tema de si la ciencia política ayudaría a modelar el contexto por el cual ella misma se ve influenciada (Gunnell e Easton, 1991:5).

En los debates desarrollados, se ha colocado especial acento en cómo el grado de crecimiento de la ciencia política y su sentido de identidad depende de un contexto político, en el cual exista amplio acceso al a información e, inclusive, a los centros donde se produce la toma de decisiones. Se ha observado que, en determinados casos, no existiría una relación causal entre democracia y ciencia política, sino más bien de tipo dialéctico y co-relacional, dado que la ciencia política puede 
emerger y florecer tanto en regímenes autoritarios como democráticos. Por otra parte, resulta de interés indagar cómo la disciplina puede contribuir a la instauración y posterior evolución de la democracia en determinados países. Para el caso de Chile, dos trabajos exploran estas dimensiones. Por una parte, Lechner (1990) ha reflexionado acerca de lo que él denominó "las condiciones políticas de la ciencia política" en Chile. Su tesis central es que la ciencia política chilena se caracteriza por una doble paradoja: en primer lugar, por un fuerte desarrollo del análisis político, en contraste con una precaria institucionalización de la disciplina. Los resultados relevantes se han producido al margen de la lógica interna de la disciplina. Es el contexto político el que contribuye a este estado de cosas. A su juicio, la dictadura provocó una reestructuración institucional que dio lugar a estudios políticos de calidad y utilidad que, en conjunto, no configuran una disciplina. Ello ayudaría a entender la escasa autorreflexión de los cientistas políticos acerca de su práctica. En segundo término, llama la atención acerca de la débil institucionalización de la ciencia política en un país como Chile, que se ha distinguido tempranamente por una temprana y fuerte institucionalidad. Advierte, asimismo, cómo el origen positivista de las ciencias sociales en Chile y la más reciente influencia del marxismo confluyen en resaltar el uso práctico del conocimiento social.

Puryear (1994) ha realizado un estudio sistemático de cómo los intelectuales chilenos, aglutinados en centros de estudio, jugaron un rol importante en la transición democrática, sin parangón en América Latina. Explora las maneras en que dicha contribución se realizó y los factores que explicarían el surgimiento de intelectuales -especialmente sociólogos, economistas y cientistas políticos- como actores políticos.

Las respuestas de nuestros entrevistados son coincidentes con estas apreciaciones. En general, se reconoce que, en ciertas condiciones, la ciencia política puede desarrollarse sin traumas bajo un régimen autoritario, como fue el caso de Chile. Efectivamente, las instituciones más antiguas de la disciplina se asientan en los años del régimen militar e inician sus programas de Magíster. Su desarrollo en democracia también puede verse en aprietos: no en vano se recuerda cómo fue abortada por los efectos de la polarización ideológica de la década de los años 60. Durante los años 80, hubo mucha actividad, expresada en publicaciones, dada la disponibilidad de recursos de organismos extranjeros y la clausura de la docencia, que permitía tiempo para la investigación, pero se duda de si eso representa efectivamente autonomía. Se habla de ese tiempo como de uno de "autonomía relativa" para la ciencia política. Hubo una aglutinación temática en torno al debate "dictadurademocracia", que generaba un efecto galvanizador, en un contexto en el que los centros académicos independientes no eran solamente un espacio laboral, sino también un lugar de resistencia política, sociabilidad y de desarrollo de afectos. Se reconoce unánimemente el papel jugado por FLACSO. En algunos casos, se afirma que la década de los 80 no llega a compararse con la instalación de las Ciencias Sociales a fines de los 60, que era una empresa internacional y que intencionó la formación en sociología y en ciencia política en perspectiva científica (ELAS, ELAP). La democracia no habría traído el mejor de los mundos para la ciencia política: la lógica de mercado lleva a la consecución de recursos por la vía de los concursos; las universidades no reintegraron los espacios de investigación anteriores y buena parte de los investigadores pasaron a engrosar las filas de los funcionarios de gobierno de la recién conquistada democracia, produciéndose lo que algunos no dudan en llamar "jibarización", "mutilación", "sangría", "cooptación" o, en tonos más elegantes, "trasvasije" o "migración intelectual hacia el Estado". 
No es menor la dificultad que se presenta cuando pretendemos analizar la ciencia política aisladamente. Lo que se ha denominado "relaciones entre las disciplinas científicas como problema" ha sido observado en el marco de los dilemas metodológicos del estudio comparado de la disciplina. Se señala que debe hacerse la distinción entre estudios y análisis político, en sentido genérico y ciencia política como un modo de indagación y de práctica histórica y académicamente situada. Esta segunda opción no estaría exenta de implicancias normativas por cuando se entendería que la ciencia política "madura" es la que más se acerca al modelo americano. Sin embargo, enfrentar esta situación es algo evitable para los historiadores disciplinarios, por cuanto parece imposible concebir una historia de la ciencia política y de sus tendencias actuales sin referencia a las otras ciencias sociales (Berndtson, 1991:49; Easton et al., 1995: 13; Dogan, 2001:151). Para el caso chileno, se señala que "en los años 80 , nadie pregunta por la disciplina. Había una tendencia hacia lo interdisciplinario. Flisfish y yo hacemos una mezcla de sociología y de ciencia política. Lo que pasa es que los sociólogos hacen ciencia politica. Eso te responde a la situación de la ciencia política en Chile". Es más, se reconoce la necesidad de reflexionar acerca de los aportes históricos realizados a la reflexión política de larga data: "Me parece escandaloso que no se pueda acceder a ediciones modernas de las obras de autores como Bilbao, Lastarria, Egaña, Julio César J obet y Luis Emilio Recabarren. Quienes los estudian son los historiadores y lo hacen en una perspectiva histórica, y no de historia de las ideas políticas. Pensar en la Ciencia Política a partir de los años 60 no es apropiado".

Encontramos posiciones más radicales sobre la relación entre la disciplina y la democracia:

El decir que hay una relación especial entre la política democrática y la Ciencia Política es inexacto, y refleja una visión ideológica, muy común en la ciencia política norteamericana, ligada al elitismo democrático. El período más rico de la ciencia política latinoamericana es el de la emergencia de regímenes autoritarios, con trabajos como los de O`Donnell sobre el autoritarismo burocrático y los análisis de Garretón sobre el caso chileno.

No se produjeron desarrollos disciplinarios duros, no hay creación de teoría. Hay que analizar el pasado con espíritu más crítico, no tan nostálgico. Había gran valor en la ciencia social que se estaba haciendo, que no apuntaba al desarrollo disciplinario, sino a la capacidad analítica, con la demanda puesta en la situación que se vivía.

La ciencia política hoy se quedó sin tema. No logró reposicionarse ni avanzar. Tomó la democracia como punto de llegada, en los 90, y no como un proceso. Ahí juega mucho la autocensura de gente de mi generación, que vivió en 1973. La idea era no levantar olas (... ).

Se constata un cierto grado de irrelevancia disciplinaria cuando se afirma que "la democracia ha influido poco en la ciencia política y ésta ha influido menos en la democracia. Incluso, la incapacidad de cuestionar el momento actual como realmente democrático, cuando se sabe que no lo es, la ciencia política no lo descubre, no haciéndose cargo de temas éticos que, dicho sea de paso, son parte de la epistemología y de la metodología", o cuando se afirma que "la ciencia política se va quedando atrás de lo que señala la agenda, sin observar los desafíos que presenta la sociedad y el sistema político". 


\section{LA CONCEPTUALIZACIÓN DE LO POLÍTICO O UNA DISCIPLINA EN BÚSQUEDA DE UN NORTE}

Resulta de interés auscultar las posibles áreas de preocupación intelectual que han concertado los esfuerzos de los cultores de la disciplina, las herramientas conceptuales y las implicancias de posibles discusiones metodológicas, así como las concepciones subyacentes de filosofía de la ciencia a la base de estos esfuerzos. Son muy escasos los intentos de identificación de los ideales explicativos y los paradigmas de uso más recurrente en América Latina y en Chile, en particular (Lechner, 1990: 13; Werz, 1995:136).

En general, los entrevistados constatan que la ciencia política es una disciplina de reciente desarrollo (a partir de la Segunda Guerra Mundial, en los países avanzados) y que en Chile estaría todavía en su infancia.

Los cientistas políticos entrevistados coinciden en señalar la carencia de debates intelectuales en el marco de la ciencia política chilena. No existiría propiamente una comunidad. También se observa un escaso desarrollo sistemático de los paradigmas disciplinarios, salvo la tradición institucionalista y de teoría política europea. Se valora el esfuerzo individual de algunos que están realizando estudios en la tradición del nuevo institucionalismo, que resulta muy afín a la tradición chilena.

Se reconoce una ausencia de estándares de trabajo y el tamaño reducido del medio desemboca en una transversalidad de la disciplina, lo que se aprecia como positivo, ya que se produce hibridación y cruces (como el trabajo de Manuel Antonio Garretón, que señala como ejemplo). A pesar de lo anterior, se supone como natural el que el ideal explicativo de la Ciencia Política contemporánea viene dado por la democracia y sus instituciones.

Sin embargo, algunas apreciaciones son ciertamente críticas:

La disciplina inició su desarrollo con una nota alta durante el siglo pasado. Cayó en los años setenta. La verdad es que no se ha desarrollado. Esto no es el modelo de Rustow, de precondiciones, despegue y modelo de progreso. Diría que se encuentra en una constipación permanente.

La disciplina se encuentra sin objeto de estudio. En dictadura, los objetos de investigación eran el régimen militar, luego la democracia y, posteriormente, la transición. Ambos temas están caducos.

Resulta difícil desarrollar un pensamiento cuando todo está tan difuso en términos de clivajes políticos. No tienes enfrente un pensamiento al que puedas contrastar, con el que se polemice $(\ldots)$.

Los ideales que podríamos tener pueden venir desde nuestros historiadores, no desde los cientistas politicos. Hablo de personas como Aníbal Pinto o J aime Eyzaguirre. Nuestras mallas curriculares han sido un reflejo de los eventos mundiales más importantes pero que no se conectan con la realidad chilena.

Algunas opiniones se centran en los problemas a enfrentar, particularmente en las agendas de investigación de la disciplina: 
Observo una obsesión por los estudios electorales, por el sistema electoral, ni siquiera por el comportamiento electoral. El trauma por el binominalismo se ha convertido en una obsesión que impide el surgimiento de nuevos temas. Luego, padecemos del parroquianismo de los americanos y de una visión americano-centrista de los temas políticos. Enseguida, adolecemos de una perspectiva comparativa y un cierto parroquianismo nacional.

Tiene que privilegiarse la ciencia básica porque, de ahí, emerge la capacidad de creación del conocimiento. Una sociedad tiene que definir su estilo: si quiere crear conocimiento o si quiere nutrirse de forma derivativa.

Hoy se habla mucho de la interdisciplinariedad pero, para que ello ocurra con consecuencias prácticas efectivas, tiene que haber un desarrollo disciplinario previo. Si no es así, se produce la hegemonía de los paradigmas que están controlando la investigación.

Una manera indirecta de conocer enfoques y escuelas de pensamiento, así como modelos, teorías y métodos que pudieran ejercer influencia en los cientistas políticos es indagar cuáles con las revistas disciplinarias que usualmente consultan en su trabajo. Paradójicamente, la American Political Science Review es la más nombrada, pero lo curioso es la ambivalencia que genera: adoración y rechazo. Ello se grafica en expresiones tales como "La APSR la leo siempre. En general, me gustan las revistas americanas. Creo que es ahí donde se está liderando nuestra disciplina. Constituye la producción más importante y lo que se hace en otros lugares, si vale la pena, es inmediatamente recogido", "primero que nada consulto mi Biblia, que es la APSR", "la APSR no la consulto mucho. Tiene una visión disciplinaria un poco estrecha y a mí me interesa más la visión interdisciplinaria", "no veo la APSR, donde aparece como más importante el dato que la idea" o "consulto todas las revistas, menos la APSR. De su vuelta, en los años 70, a una forma de empiricismo extremo, no me atrae. La veo por encima".

El resto de las revistas más mencionadas son Political Theory, Comparative Politics, World Politics, J ournal of Democracy, Government and Opposition, Foreign Affairs y Foreign Policy. Un fenómeno a estudiar es el aparente desgano que generan las revistas disciplinarias autóctonas, aunque se reconoce que la Revista de Ciencia Política de la Pontificia Universidad Católica ha experimentado un mejoramiento y que la de mayor calidad es la revista Estudios Públicos, siendo miscelánea.

De estas confesiones se desprende una útil cantera de investigación: las obras. Un estudio de influencia bibliográfica referencial permitiría identificar influencias por autores, países, enfoques, así como las posibles contradicciones.

\section{HEGEMONÍAS DISCIPLINARIAS O EL PESO DE LA INFLUENCIA AMERICANA}

En el marco de los debates impulsados por los "nuevos historiadores disciplinarios", uno de los que ha concentrado considerable atención es el relativo a la influencia del molde americano de la ciencia política en el resto del mundo y hasta qué punto se puede seguir hablando de una ciencia americana de la política, en condiciones en que ésta, desde mitad del siglo pasado, ha emigrado a distintos contextos, recibiendo la influencia de los componentes locales (Gunnell, 2002). De hecho, también autores como Berndtson (1991:48) se han referido a la "americanización" como un problema metodológico a enfrentar en el campo de la investigación comparada, indicando que debe ser evaluado caso a caso, evitando el uso de simples teorías de influencia. 
Nuestros cientistas políticos, en general, reconocen la dificultad de escapar a esta influencia, que alguno llega a catalogar de incontrarrestable, por un asunto de magnitud y de calidad de la producción disciplinaria americana, apresurándose a advertir la ausencia de preferencias ideológicas de algún tipo. Otros plantean opiniones matizadas:

Si hubiera un modelaje americano, sería ambiguo y no se ha traducido en escuelas, aunque el Instituto de ciencia política de la Universidad Católica de Chile copió el modelo de Georgetown para su Programa de Magíster.

Influyó mucho en un momento, cuando se estaban haciendo trabajos analíticos. Hoy, observo una creciente brecha. La ciencia política americana se está poniendo demasiado técnica, con los modelos (... ). Si uno no puede leer la APSR, no está en ese tipo de ciencia.

Dada la tradición de pensamiento más europeísta existente en Chile, no creo que se imponga la tradición americana, aunque sí están llegando nuevas generaciones con las más modernas metodologías de análisis. Ello ayudará a profesionalizar la disciplina.

La ciencia política americana es demasiado grande para ser ignorada pero en Chile existe un grupo pequeño, pero significativo, de personas que hemos estudiado en Europa y que no nos dejamos llevar por el mainstream americano, que es la tontería cuantitativista o guiarse por el modelo de comportamiento electoral norteamericano.

Se señala que hemos sido influidos particularmente a través de temáticas:

No hemos sido capaces de levantar nuestros propios temas. Ni siquiera el tema de la transición, dado que nosotros entramos en el estudio de la oleada de las transiciones, que ya estaba instalado.

El Instituto de Ciencia Política de la Pontificia Universidad Católica de Chile sería el referente institucional más marcado por esta influencia:

La ciencia política de este Instituto y de varias otras entidades académicas de hoy han recibido y siguen recibiendo un estilo, una impronta docente y una investigación típicamente anglosajona, norteamericana más precisamente. Y, al día de hoy, es fuertemente tributario de la tradición norteamericana.

Efectivamente, todo comenzó en dicho Instituto, pero yo tuve la intuición de no enviar a toda la gente a estudiar a Estados Unidos, sino también a Inglaterra y a Alemania.

Los cientistas políticos chilenos, en general, parecen resignados a esta hegemonía. Sin embargo, el debate está latente: no sólo en lo que respecta a la hegemonía americana de la ciencia política, sino a las aspiraciones de unilateralidad de sus enfoques predominantes: el behavioralismo y la elección racional, que descansan en una epistemología positivista. Es una tarea pendiente conocer y, eventualmente, vincularse a los debates en curso que aspiran a una ciencia política más cosmopolita en sentido de admitir mayores dosis de pluralismo teórico y diversidad cultural. A pesar del incremento de los contactos internacionales entre las comunidades politológicas americana y europea, los avances han sido magros (Norris, 1997; Marsh y Savigny, 2004). 


\section{LA POLÍTICA Y LAS AULAS}

Todo cientista político pareciera tener presente la célebre recomendación de Weber (2002:212) según la cual la política no tiene cabida en las aulas. Fue taxativo en indicar que la toma de posición política y el análisis científico de los fenómenos y de los partidos políticos son dos cosas bien distintas. A su juicio, el hombre de ciencia que permite que se introduzcan sus propios juicios de valor deja de tener una plena comprensión del tema.

La visión weberiana tradicional ha sido objeto de polémica, preguntándose por los objetivos que debería perseguir el profesor de ciencia política en referencia al rol actual o futuro de los estudiantes como participantes u observadores de la política. También se cuestiona la afirmación de si la enseñanza de la ciencia política es, en sí misma, un acto político (Van Dyke, 1977:vii). Ya Robson (1961: 83) advertía que el profesor de la disciplina no puede librarse de la parcialidad, reconociendo la existencia de dos tipos de especialistas en ciencia política: los conscientes de sus tendencias políticas y los que no las reconocen. Y los segundos, a su juicio, son mucho más peligrosos para los estudiantes que desean adquirir conocimientos políticos válidos y formar juicio en este aspecto.

Dado que la ciencia política en Chile tiene una "connotación superacadémica", como la califica uno de nuestros entrevistados, de manera que la inserción profesional natural e indiscutible pareciera ser, en nuestro contexto, la docencia y la investigación, emerge como un tema relevante pesquisar las visiones existentes sobre este tema, y frente a las que no se descubre unanimidad. Así, algunos adscriben fielmente a la postura weberiana cuando afirman que "es una regla de oro. Trato de no hacer ver mi posición sobre un tema aunque es imposible la asepsia absoluta. En todo caso, esto lleva a una actitud académica de lo político y poco militante. Llama la atención que nuestros estudiantes de ciencia política sean poco militantes, algo generalizado entre los jóvenes, pero son costos que estoy dispuesto a pagar. No estamos entrenando a militantes, sino a cientis tas políticos" o cuando se señala "yo siempre he tratado de que mi posición política-partidista no se trasluzca".

Sin embargo, otras posturas plantean lo siguiente:

Soy totalmente partidario de que el profesor explicite sus tendencias políticas, no ocultarlas de hecho. Ese discurso, un tanto ridículo, de entregar una ciencia política en una perspectiva científica oscurece el hecho de que no hay objetividad en los temas que analizamos. La definición que el profesor hace de la partida, no condiciona el debate. La experiencia norteamericana al respecto es interesante, dado que los profesores recurren mucho al juego de roles, con tomas de posición fundamentadas.

Algunos visualizan cómo debiera estructurarse la reproducción disciplinaria, a partir de la creciente emergencia, desde la década de los 90 , del nivel de formación de pregrado:

La disciplina, desde que se instaura hasta la fecha, tiene todavía una corta vida en Chile, por lo que no se consolida ni se instaura plenamente. En todo este período, aquellos que la han cultivado lo han hecho en tanto académicos y, en segundo lugar, están aquellos que han hecho cursos de Magíster con la intención de fortalecer su currículo profesional o académico. Ya existe la Licenciatura, que ofrece un título profesional y solamente en una tercera fase, 
a la cual estamos entrando ahora con las Licenciaturas y, posteriormente, con el Doctorado, la disciplina va a adquirir otro cariz. Tendrá todos los ladrillos de la formación.

Algunos entrevistados perciben un sesgo autoritario en el ejercicio de la docencia. Se señala que, para el caso de Chile, "el rol del alumno debería ser más protagónico y el profesor tiene que ser un facilitador, que promueva el contacto personal. Lo que se percibe en todas partes es hielo y distancia y se explica en cómo la dictadura afectó a la universidad. Falta comunidad" o "se entronizó aquí un temor colectivo. La gente no quiere revelar sus opiniones políticas, ni siquiera en una clase. Tenemos una juventud retraída y, por tanto, la docencia debe ser observada en términos históricos".

Otros consideran que la disciplina es genéticamente autoritaria,

dado que es una de las más conservadoras y autoritarias que existen. La prueba de ello es que, en los regímenes autoritarios, se persigue primero a la sociología y la ciencia política tiende a ser tolerada, particularmente en su manifestación ingenieril, que es la administración pública. En su variable internacional, esto es concordante, porque se percibe como una disciplina imperial. Ha sido enfocada desde la perspectiva de los reyes, a caballo 0 a pie, y desde los mercaderes, pero no hay una teoría política real que se haga desde el punto de vista del ciudadano, de la ciudadana, de la gente.

Otros entrevistados van más allá y señalan que

la ciencia política es una disciplina de segundo grado, en el sentido de que su utilidad se evidencia cuando se posee otra disciplina social previa, tales como historia, sociología, economía, que entregan otras bases para analizar a fondo la política. Es una disciplina que supone otras formas de comprensión, y se parece en esto a la Filosofía. Ello implica también un nivel de comunicación más elaborado que otras disciplinas sociales, lo que puede colocar al profesor en una situación de superioridad, pero también sus ideas y conceptos son menos exactos, más provisionales.

Frente a las expresiones vertidas, pareciera razonable acoger la afirmación de Lasswell (1971:173), según la cual debemos estar dispuestos a aceptar que hay distintos modos de dar clase que atraen a distintos estudiantes y que parte del problema de un programa de enseñanza en ciencia política consiste en crear un medio ambiente de personalidades distintas y poderosas que compartan una común dedicación intelectual al tema y que otorguen la oportunidad de comprender el estímulo intelectual y personal que entraña la disciplina.

\section{LA CIENCIA POLÍTICA, SU LEGITIMIDAD Y UTILIDAD SOCIAL}

Lasswell (1971:186) señaló en su momento la existencia de una ambigüedad de la imagen del especialista en ciencia política, constatando la existencia de una cierta "holgura" con la que muchos individuos se han identificado con su desarrollo, a raíz de la constatación de la inexistencia de un código escrito de comportamiento profesional. Dada esta impresión profesional un tanto grisácea, resulta de interés auscultar cuál sería la función social y el sentido de relevancia de su quehacer, para los propios cientistas políticos. Esto se traduce en indagar acerca de cómo los politólogos visualizan las maneras en las que la función de la ciencia política ha sido concebida y 
puesta en práctica en la sociedad. No existen mayores estudios empíricos al respecto. Sin embargo, entre las excepciones en este ámbito vale la pena destacar a Trent (2003), que se ha preocupado de explorar acerca de cómo la perciben los burócratas y los políticos, los que personifican al Estado, objeto de estudio de la ciencia política. De manera más específica, ha investigado acerca del conocimiento que éstos tienen de nuestro objeto de estudio, acerca de la base institucional y profesional, de la política científica y de investigación, los vínculos personales con la ciencia política y sus actitudes acerca de la disciplina, tanto en su ámbito docente como de investigación, entre otros aspectos. Por otra parte, Newton y Vallés (1991:230), para el caso de la ciencia política en Europa occidental, se han preguntado acerca de cuál sería el impacto de la ciencia política en la sociedad en la búsqueda de evidencias de influencia. Analizan el impacto en los gobiernos, en los medios de comunicación y en la vida intelectual, en los programas de educación cívica y en otras disciplinas. Concluyen afirmando que la ciencia política y quienes la practican tienen una influencia difusa que supera el pequeño número de personas que la cultivan, y que ésta podría crecer si obtiene un mayor status profesional. Pero esto tendría un costo: una mayor influencia en el entorno conllevaría una menor profesionalización, la preocupación por dirigirse a un público más amplio tendría, como consecuencia, una postergación del desarrollo del lenguaje, conceptos, cuestiones y métodos propios de la ciencia política. ¿Es el mismo caso para Chile?

Sintomáticamente, algunos entrevistados coinciden en señalar que el politólogo carece de un rol institucionalizado, a diferencia de otras profesiones y, en esto, se asimilaría al sociólogo. Por otra parte, la percepción dominante en América Latina, se señala, la circunscribe a una actividad académica, sin gran utilidad social, lo que sería erróneo. Se avanza en señalar que hay un problema de número:

hay pocos programas de pregrado, pocos cientistas políticos todavía y, en algunos lugares como el sector privado, son mirados con sospecha, dado que se piensa que la persona que llegue desde esa profesión es un militante 0 un activista. Por otra parte, juega en contra el aislamiento en el que viven los políticos, que no se vinculan con el mundo de las ciencias sociales y el hecho de que todo el mundo se siente autorizado a opinar sobre política.

En cuanto a estrategias futuras de la disciplina, se proponen distintas alternativas: desde la responsabilidad que les cabe a los Institutos tradicionales de ciencia política en Chile, "haciendo investigación sobre temas relevantes, y no solamente docencia, así como buscar coaliciones con disciplinas cercanas, evitando el aislacionismo. El trabajo con la Economía es importante, dada la preponderancia que tiene en Chile", hasta afirmar que

lograr mayor legitimidad social es el desafío de quienes estamos formando cientistas políticos ya que nosotros no lo tenemos suficientemente claro. Vislumbro dos grandes áreas de trabajo: el sector público, donde tienen la función de asesoría en la toma de decisiones políticas, a distintos niveles, y en el sector privado, con conocimiento de cómo se toman las decisiones empresariales, económicas, sobre cómo funciona el sistema y cómo lograr una mejor inserción dentro del mismo, con particular énfasis en la evaluación de riesgos de inversión.

El posicionamiento de la ciencia política en los medios de comunicación genera comentarios ambivalentes, bien de cautela, bien de celebración: 
Ser serios es indispensable y, cuando se tiene presencia pública, debe hacerse un comentario distinto a un periodista. Me temo que los que suelen tener más presencia pública no son los más sólidos dentro de la disciplina.

En Inglaterra, yo había visto a un tipo de intelectual que se desconocía en Chile, en donde se oscilaba entre el intelectual orgánico, vinculado a los partidos, o bien el intelectual de "torre de marfil", evitando desde la universidad toda opinión y controversia. Pero observé que había un tercer tipo, la mayor parte como comentaristas de la BBC, que tenían una opinión sobre la coyuntura, en un plano de gran independencia, que aportaba su conocimiento y lo hacía desde un plano ético. En esa perspectiva me surgió, de repente, la oportunidad de incursionar en los medios de comunicación.

En esta sociedad mediática, aparecer en los medios debería ser una obligación de todo cientista político. Tener su nicho.

Se señala, sin embargo, que la posible utilidad de las ciencias sociales en general, y de la ciencia política, en particular, viene mediatizada por el tipo de desarrollo que ha tenido el país. El problema no estaría radicado solamente en un desfase de velocidades entre la disciplina y las preguntas que se hace la sociedad, sino que sería estructural. Una opinión es enfática en este sentido:

Las ciencias sociales estuvieron vinculadas al desarrollo, con un rol y aporte importante en torno a éste. La hegemonía del pensamiento económico neoclásico, a partir de los años ochenta y hasta hoy, es asfixiante y produce la ruptura entre ciencias sociales y desarrollo. La consecuencia es que no son consideradas como un aporte y, por otra parte, se instala un pensamiento único que no considera necesaria ninguna otra visión. La disciplina funcional a estos efectos es la economía, con una concepción excluyente y marginalizadora de cualquier otra visión que pretenda complementarla o rebatirla.

Algunos indican que, inclusive, el espacio natural y aparentemente consolidado de la docencia es un ámbito riesgoso:

No existen condiciones materiales para el ejercicio y praxis de la disciplina. No existen incentivos adecuados: no existe un Fondecyt para las ciencias sociales, no hay carrera académica en el sentido estricto del término y no hay jerarquías ni estímulos adecuados para la producción intelectual o esta disciplina no escapa de lo injusto del sistema de premios y castigos existente en Chile, donde los sistemas de reconocimiento siguen formas anómalas.

El desarrollo de la ciencia política en Chile es, en sí, un caso de estudio que debiera insertarse en análisis comparados de historiografía disciplinaria en perspectiva comparada. Así se reconoce en Easton et al. (1995:22) cuando, a la hora de estudiar el rol jugado por los cientistas políticos en los escenarios post autoritarios, se señala la característica fragmentada del sistema de educación superior (universidades estatales vs. privadas, instituciones seculares vs. de Iglesia, centros de investigación universitaria vs. institutos independientes de investigación), así como las inadecuaciones del gobierno y de las fundaciones extranjeras donantes, produciendo un debilitamiento y una falta de dirección disciplinaria. 


\section{LOS REFERENTES INTELECTUALES Y LAS COHORTES GENERACIONALES}

Cuando nos interrogamos acerca del desarrollo de la ciencia política, surge el interés de indagar acerca de la influencia relativa que algunos individuos pueden haber ejercido, versus al papel de las instituciones (Easton et al., 1995:7). Los entrevistados sugirieron nombres a la respuesta de las personas más relevantes e influyentes en el desarrollo de la ciencia política, en un sentido más general. Pero también conviene destacar los nombres de personas que parecen haber ejercido una influencia fundamental en la elección de la disciplina como ámbito de estudio y ejercicio profesional posterior, mencionados en forma espontánea.

En esta línea, merece ser destacado Oscar Godoy, cuyo número de menciones es notorio. Enseguida, se resalta la influencia de Arturo Valenzuela, Norbert Lechner, Carlos Huneeus, Tomás Moulian y Manuel Antonio Garretón. Entre los que se denominan "jóvenes promesas disciplinarias" resalta el número de menciones que reciben Alfredo J oignant y Patricio Navia. Dentro de una visión amplia de la reflexión política, varios entrevistados no dudan en destacar los aportes de Anibal Pinto o Enzo Faletto.

Por otra parte, entre los individuos que han ejercido un rol inspirador para que otros siguieran la senda del estudio de la ciencia política se encuentran Carlos Fortín, Gustavo Lagos, Edmundo Fuenzalida y Luciano Tomassini.

Un elemento importante en la construcción de cualquier autoimagen disciplinaria pudiera ser la identificación de grupos de personas, inscritas en lógicas generacionales en función de distintos criterios. Para el caso de la ciencia política, sin embargo, el 11 de septiembre de 1973 parece haber surtido el efecto de un "tsunami", dada la radicalidad con que la mayoría de los entrevistados reconoce que este evento político marcó su trayectoria vital, en todos los ámbitos, no sólo el profesional. Un entrevistado lo revela meridianamente:

Creo que hay un solo corte, dictadura-democracia, que simplifica el cuadro de manera excesiva. Sucede que ahora estamos transitando a la posibilidad de incluir otros cortes a futuro y eso guarda relación con los lugares de formación y con la diversificación de la formación en Chile.

Sin embargo, algunos entrevistados incorporan una primera generación, la de los precursores 0 padres fundadores de la disciplina, y en cuya conformación no pueden realizarse distinciones disciplinarias nítidas todavía. Tal es el caso de Gustavo Lagos, de quien se señala como relativamente autoformado en el campo de la disciplina, con gran capacidad integradora y proveniente de otras disciplinas y perspectivas.

Los acontecimientos políticos también incidieron en las posibilidades formativas, dependiendo de la salida al exilio o la permanencia en el país. En el primero de los casos, y como una derivación no buscada de la violencia política, surgió la posibilidad de realizar estudios de postgrado. Sin embargo, se coincide en señalar que la existencia de distintas cohortes se asienta en un funcionamiento personal, más que en una agrupación por escuelas. Se puntualiza que "lo generacional está definido por un período, por un momento, no por una continuidad temática".

Se afirma que no habría existido discipulado en Chile.

La dictadura y la cooptación estatal son, esencialmente, dos factores que meten ruido e inhiben el discipulado. En realidad, no había en un tiempo unidades académicas que enseñasen la disciplina. Llegaban cientistas políticos, se juntaban entre ellos, hacían sus seminarios y sus Congresos, pero internamente. Los programas de estudio empiezan a aparecer en 
forma tardía y recién ahora regresan personas que estaban haciendo sus Doctorados. También conspiró contra ello la inexistencia de espacio para la carrera académica.

Uno de los entrevistados menciona la existencia de una "generación bisagra": aquellos cientistas políticos, cerca de la cuarentena, que ocupan cargos de responsabilidad académica en las instituciones de enseñanza e investigación y que están atentos a reintegrar a las nuevas generaciones que se encuentran en formación de postgrado en el exterior como la piedra angular de la generación de comunidades académicas sólidas y profesionales.

\section{CONCLUSIONES: APRENDER A MIRARSE EN EL ESPEJ 0}

El presente artículo tuvo por objetivo mostrar las condiciones de posibilidad del uso del enfoque internalista a la hora de comprender e interpretar el pasado de la ciencia política chilena mediante el recurso a entrevistas semiestructuradas. Se ha planteado que la opción por el uso de dicho enfoque significaría una distribución de énfasis, colocando el acento en las dinámicas intelectuales que son connaturales a la disciplina y su estructura de discurso y éste aparece como el predilecto en la empresa intelectual más amplia de comprensión del estudio de la Ciencia Política que se está impulsando, con carácter trasnacional, a instancias de la Internacional Political Science Association (Easton et al., 1995).

Se ha señalado que los cientistas políticos tienen, con frecuencia, falta de confianza en su propia empresa intelectual. Una de las razones pudiera ser que sus contribuciones, a menudo, no son reconocidas por carecer de un núcleo teórico aceptado o un método consensuado, a diferencia de otras disciplinas (Katznelson y Milner, 2002:1; Laitin, 2004: 367). También se ha precisado que existe poca evidencia de que la dirección básica de la disciplina esté determinada por imágenes de su historia, pero la historia del campo disciplinario permanece como una dimensión importante de reflexión crítica y de identidad sobre la teoría y la práctica de la disciplina que no es posible soslayar (Gunnell, 2002: 274).

La ciencia política en Chile se encuentra en un punto importante de inflexión, aunque paradójica: oferta abundante de programas de formación de pregrado, debilidad institucional que afecta las condiciones de la investigación, retorno de cientistas políticos con formación de postgrado, presencia creciente de sus cultores e influencia en la opinión pública a través de los medios de comunicación y la inminente posibilidad de que se instale un programa de Doctorado en el país, entre otros aspectos. Se percibe una creciente demanda por profesionalización (Norris, 1997: 2), entendida como el desarrollo de un cuerpo creciente de conocimiento que define el objeto de la disciplina, el reclutamiento, el entrenamiento y la certificación bajo estándares reconocidos (usualmente es el Doctorado) que certifica que los individuos se han calificado en un cuerpo de conocimiento, el empleo full-time de los académicos como docentes e investigadores en el campo, la promoción de acuerdo a estándares profesionales (publicaciones reconocidas y premios) bajo un proceso interno de revisión de pares y la organización formal de la disciplina en sociedades de conocimiento, en orden a defender los intereses de sus miembros y promover el estatus de la disciplina. El desafío es avanzar en una empresa colectiva con sus propias fronteras formales, recompensas y carreras, en el contexto de un sistema académico de mercado a nivel nacional.

Si la presente aproximación histórica, que no pretende ser más que una de las muchas narrativas posibles del pasado colectivo intelectual, contribuye a hacer a sus cultores más confiados en sus tareas, aun reconociendo sus diferencias en el marco de una disciplina fragmentada, y más sensibles acerca de la necesidad de reflexionar sobre la futura dirección de la disciplina, su necesidad de 
estándares de calidad comúnmente admitidos y su progresiva profesionalización y una autoconciencia acerca de los requerimientos teóricos de la investigación, habrá cumplido su cometido.

\section{REFERENCIAS}

Adcock, Robert y Mark Bevir. 2005. "The history of Political Science". Political Studies Review 3: 1-16.

Almond, Gabriel. 2001.

Anckar, Dag y Erkki Berndtson. 1987. "Introduction". Internacional Political Science Review, 8: 1-7.

Baer, Michael et al. 1991. Political Science in America. Oral histories of a discipline. Lexington: University Press of Kentucky. Barrios, Alicia y J osé J oaquín Brunner. 1988. La sociología en Chile: instituciones y practicantes. Santiago: FLACSO.

Berndtson, Erkki 1991. "The development of political science: methodological problems of comparative research". En The development of Political Science, editado por D. Easton et al. London: Routledge, 34-58.

Brunner, J osé J oaquín y Alicia Barrios. 1987. Inquisición, mercado y filantropía. Ciencias Sociales y autoritarismo en Argentina, Brasil, Chile y Uruguay. Santiago: FLACSO.

Brunner, J osé J oaquin. 1985. La participación de los centros académicos privados en el desarrollo de las Ciencias Sociales. Santiago: FLACSO.

Brunner, J osé J oaquín. 1988. El caso de la Sociología. La formación de una disciplina. Santiago: FLACSO.

Brunner, José J oaquín. 1989. Ciencias Sociales y Estado: reflexiones en voz alta. Santiago: FLACSO.

Courard, Hernán y Alicia Frohmann. 1999. Universidad y Ciencias Sociales en Chile, 1990-1995. Santiago: FLACSO.

Cansino, César. 1999. La Ciencia Política de fin de siglo. Madrid: Huerga y Fierro Editores.

Daalder, Hans. 1997. Comparative European Politics: the store of a profession. London: Pinter.

Dogan, Mattei. 2001. "La Ciencia Política y las otras ciencias sociales". En Nuevo Manual de Ciencia Política, editado por Robert E. Goodin y Hans-Dieter Klingemann. Madrid: Ediciones Istmo, 150-196.

Easton, David et al. 1995. "Introduction: democracy as a regime type and the development of Political Science". En Regime and discipline. Democracy and the development of Political Science, editado por D. Easton et al. Ann Arbor: The University of Michigan Press.

Fernández Ramil, Ma. de los Ángeles. 2003a. “Sombras nada más? Estado, mercado y Ciencia Politica en el Chile contemporáneo". Anuario de Ciencias Políticas 1: 37-67.

Fernández Ramil, Ma. de los Ángeles. 2003b. “Twenty years of the Chilean Political Science Association”. Participation 27 (1):21-22.

Fuenzalida, Edmundo. 1983. "The reception of scientific sociology in Chile". Latin American Research Review XVIII (2): 95-112.

Fuenzalida, Edmundo. 2001. "La vinculación internacional de las Ciencias Sociales en Chile", ponencia presentada al Encuentro Nacional de Ciencias Sociales. Santiago, 14.

Garretón, Manuel Antonio. 1981. Las Ciencias Sociales en Chile al inicio de los ochenta: situación, problemas y perspectivas. Santiago: FLACSO.

Garretón, Manuel Antonio. 1989. La evolución de las Ciencias Sociales en Chile y su internacionalización: una síntesis. Santiago: FLACSO.

Godoy, Óscar y A. Vial. 1989. "Estado de la Ciencia Política en Chile". En Las Ciencias Sociales en América Latina. Entre la legitimidad y la marginación, editado por P. Dooner. Santiago: Centro Interuniversitario de Desarrollo, 297-315.

Graham, Loren et al. 1983. Functions and uses of disciplinary histories. Holland: Kluwer Academic Publishers.

Gunnell, John G. e D. Easton. 1991. "Introduction". En The development of Political Science, editado por D. Easton et al. Londres: Routledge, 1-12.

Gunnell, J ohn G. 1991. "The historiography of American Political Science". En The development of Political Science, editado por D. Easton et al. London: Routledge, 13-33.

Gunnell, J ohn G. 2002. "Handbooks and History: is it still the American Science of Politics?". International Political Science Review 23(4):339-354.

Gunnell, J ohn G. 2004. Imagining the American polity: Political Science and the discourse of democracy. University Park: Penn State Press.

Huneeus, Carlos. 1988. “Se establecerá definitivamente la Ciencia Política en América Latina? Propuestas para una respuesta afirmativa". Alternativas, 1:15-37. 
Jerez Mir, Miguel. 1999. Ciencia Política, un balance de fin de siglo. Madrid: Centro de Estudios Políticos y Constitucionales. Katznelson, Ira y Helen V. Milner. 2002. Political Science: the state of the discipline. Washingont: American Political Science Association. Kenny, Michael. 2004. "The case for disciplinary history: political studies in the 1950s and 1960s". British J ournal of Political and International Relations 6: 565-583.

Lagos, Ricardo, Norbert Lechner y Gert Rosenthal. 1991. Las Ciencias Sociales en el proceso de democratización. Santiago: FLACSO.

Laitin, David D. 2004. “'Adónde va la Ciencia Política? Reflexiones sobre la afirmación del profesor Sartori de que "la Ciencia Política estadounidense no va a ningún lado"'". Política y gobierno XI (2):361-367.

Lasswell, Harold. 1971. El futuro de la Ciencia Política. Madrid: Tecnos.

Lechner, Norbert. 1988. Los desafíos de las Ciencias Sociales en América Latina. Santiago: FLACSO.

Lechner, Norbert. 1997. "Intelectuales y política". En Los intelectuales y los dilemas políticos en el siglo XX, editado por L. Baca Olamendi e Isidro H. Cisneros. México: Triana Editores/FLACSO, 33-35.

Lechner, Norbert. 1997. "Intelectuales y política: nuevo contexto y nuevos desafíos". En Los intelectuales los dilemas políticos en el siglo XX, editado por L. Baca Olamendi e Isidro H. Cisneros. México: Triana Editores/FLACSO, 411-417.

Lechner, Norbert. 1990. Las condiciones políticas de la Ciencia Política en Chile. Santiago: FLACSO.

Lynn, Naomí B. 1983. "Self-portrait: profile of political scientist". En Handbook of Political Science, editado por Ada Finifter. Washington: APSA.

Marsh, David y Heather Savigny. 2004. "Political Science as a broad church: the search for a pluralistic discipline". Politics: 24 (3): 155-168.

Newton, Kenneth y J oseph M. Vallés. 1991. "Introduction: Political Science in Western Europe, 1960-1990". European J ournal of Political Research 20: 213-220.

Norris, Pippa. 1997. “Towards a more cosmopolitan Political Science?”. European J ournal of Political Research 30 (1): 17-34. Ortiz, Eduardo. 1999. "El estudio de las Relaciones Internacionales". Revista Diplomacia 81: 7-15.

Puryear, J effrey M. 1994.Thinking politics: intellectuals and democracy in Chile, 1973-1988. Baltimore: The John Hopkins University Press.

Robson, William A. 1961. La enseñanza universitaria de las ciencias sociales: Ciencia Política. Washington: Unión PanamericanaSecretaría General, O.E.A.

Rose, Richard. 1990. "Institutionalizing professional political science in Europe: a dynamic model". J ournal of Political Research 18: $581-603$

Sepúlveda, Alberto. 1976. "Problemas para el desarrollo de los estudios sobre relaciones internacionales en Chile". Revista Estudios Sociales 8: 30-61.

Sepúlveda, Alberto. 1996. "El desarrollo de la Ciencia Política en Chile". Revista Política 34: 135-147.

Tomassini, Luciano y Marcelo Ortiz. 1999. Evolución de la Ciencia Política a nivel nacional e internacional. Ponencia presentada en el V Congreso Nacional de Ciencia Política, Santiago.

Trent, J ohn. 2003. The relationship between the researcher and the subject matter: for a comparative study of what political and public service practitioners know about Political Science. A proposal. En XIXth World Congress of International Political Science Association, 30-J une to 4-J uly, Durban, South Africa, 1-29.

Van Dyke, Vernom. 1977. Teaching Political Science: the professor and the polity. Atlantic Highlands N.J : Humanities Press Inc. Weber, Max. 2002. El politico y el científico. Madrid: Alianza Editorial.

Werz, Nikolaus. 1995. Pensamiento sociopolítico moderno en América Latina. Caracas: Editorial Nueva Sociedad.

Wilhelmy, Manfred. 1978. "Desarrollo y crisis de los estudios de las Relaciones Internacionales en Chile", Revista Estudios Sociales, 9-26.

María de los Ángeles Fernández es Directora de la Escuela de Ciencia Política-ICSO, Universidad Diego Portales y ex Presidenta de la Asociación Chilena de Ciencia Política (2000-2002). Además, es candidata a Doctora en Procesos Políticos Contemporáneos, Universidad de Santiago de Compostela. Sus recientes publicaciones son: “Sombras nada más? Estado, mercado y Ciencia Política en el Chile contemporáneo" (2003), en Anuario de Ciencias Políticas, Universidad Arcis y "Una disciplina en busca de la profesión" (2004), en Política, Instituto de Asuntos Públicos, Universidad de Chile.

(E-mail: angeles.fernandez@udp.cl) 